\title{
Infusion Method of Administration
}

National Cancer Institute

\section{Source}

National Cancer Institute. Infusion Method of Administration. NCI Thesaurus. Code

C149577.

The technique of administration of a pharmaceutical product, usually slowly and in larger volumes than for an injection, by introducing it into the body, usually after puncturing the skin; it is usually administered intravenously, but occasionally by other routes, e.g.

subcutaneously. 